\title{
Estimate of annual incidence of undiscovered syphilis
}

\author{
W. F. FELTON \\ St. Thomas's Hospital, London, S.E.1
}

The figures on which this study has been based are those published in the Annual Reports of the Chief Medical Officer since 1917, and the Quarterly Reports issued by him to the Clinics of England and Wales from 1952 onwards.

The analysis of the syphilis returns into 'first-year acquired' and 'other infections' was first published in 1931. The return of congenital syphilis was not then broken down by sex, but was included in the breakdown by sex of 'total syphilis'. Using the congenital infection ratio of males 0.6 : females 1.0 calculated from the quarterly returns 1951-70, the estimated numbers of infections of each sex has been subtracted from 'other syphilis' for 1931-50 to produce an estimate of 'late latent and other acquired syphilis'.

The incidence of congenital infection for the decade $1931-40$ was 13 per cent. $-19,085$ cases. Of these, 7,157 were estimated to be male and 11,928 female.

Since the calculations involve the use of 30-year moving averages covering the period 1931-70, the final results can cover only the years 1960-70. Estimates of the 30-year moving average were, however, made to extend the period to 15 years.

The period under study is the 40 years, 1931-70. 'First-year discovered syphilis' is defined as the number of infections reported by clinics in England and Wales as being found in a particular year and believed to have been acquired during the previous 12 months. 'Late discovered syphilis' represents the number of infections reported and believed to have been acquired before the previous 12 months.

Of the first-year discovered infections, it is estimated that 18.4 per cent. of male and 46 per cent. of female infections were found as a result of serological tests. Thus, a notable proportion of cases, particularly in females, may have passed through the phases of maximum infectiousness despite discovery in the first year.

It is assumed that this series of cases recorded by some 200 clinics is a fair sample of the total number of cases occurring in England and Wales and that it comprises a high proportion of that total. Conversely, it is assumed that the discovered but unreported cases of first year and later infections are in the same proportions as the reported cases. No allowance has been made for cases which are never discovered or reported.

The incidence of undiscovered syphilis in any given year is necessarily unknown, though it seems reasonable to suppose that it is directly related to the number of those discovered. This study makes the assumption that the relationship is constant throughout the 40-year period and can be represented by a factor which, when applied to the correct grouping of infections discovered in the first year, gives a calculated estimate of the late discoveries of a given year. Clearly, 'the late discovery factor' $(F)$ is subject to the influence of many variables, but it may still be true that the mean may properly be represented as a constant. Any trends that may exist over such a long period may not be of such a magnitude as to upset the general value of the calculated late discoveries.

The curves for male and female discoveries in the first year and later discoveries for 1931-70 are shown in Figs 1 and 2 (overleaf). Both late discovery curves show an overall downward trend, which suggests that the decrease in syphilis described by Moore as being evident since 1860 is continuing.

This trend was interrupted during the war decade of the 1940s. There have also been minor temporary increases in the mid 1950s and early 1960s. Probably the most significant trend of recent years is the levelling off of the male late discovery curve. This may be due to the increase in male infections after the 1959 Street Offences Act which changed the law in relation to male homosexuality.

While the trend was reversed for late discoveries during the 1940s, there is no rise comparable to the sharp wartime peaks of first-year discoveries. From this it can be inferred that, if there is a constant relationship between first-year and late discoveries, then the late discoveries must be spread over many years. The period of 30 years is now postulated and it is well known that discovery can be delayed for such a length of time. 


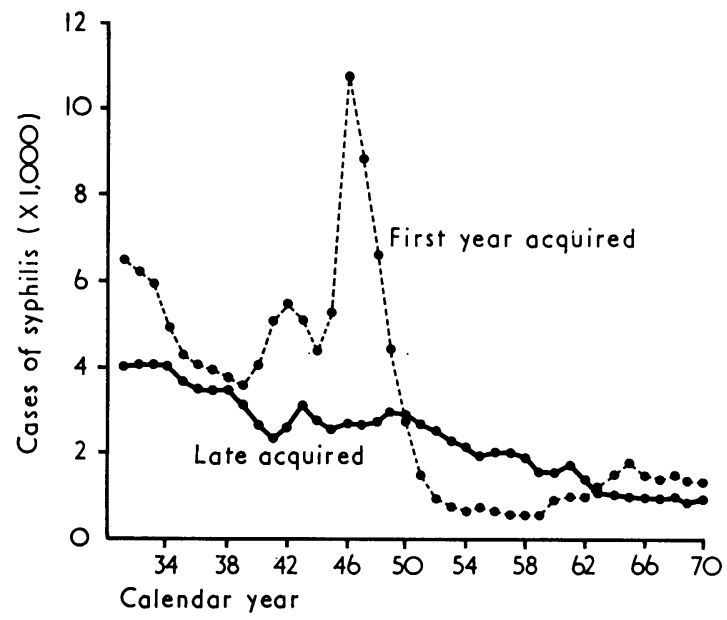

FIG. 1 Curves for males of first-year acquired discoveries and late discoveries, 1931-70

A comparison of the total figures for $1931-70$ of acquired syphilis, broken down by sex into first-year and late discovered infections is shown in Table I. A higher proportion of males ( 57 per cent.) is found in the first year. The position is reversed in females and a higher proportion ( 52 per cent.) is late discovered. It is to be noted that the proportion of late discovered males is of the same order as that of females-the actual numbers were 93,351 males and 71,490 females. Even if, during this period of 40 years, the two categories were not in equilibrium, it appears that the male and female infectious pools may have been of at least equal importance.

If the first-year and late discoveries are assumed to be in equilibrium, then a 'late discovery factor' could be calculated from the data in Table I:
(a) Males $93,351 \div 125,919=0 \cdot 741$

(b) Females $71,490 \div 66,131=1 \cdot 081$

As the 40-year period 1931-70 was influenced during the first 20 years by the increase in the first world war and the 30-year period 1941-70 by the increase in the second world war, it is not possible to know how many late discovered cases were brought in at the beginning and how many remain to be discovered after 1970 . The earlier peak lasted 2 years.

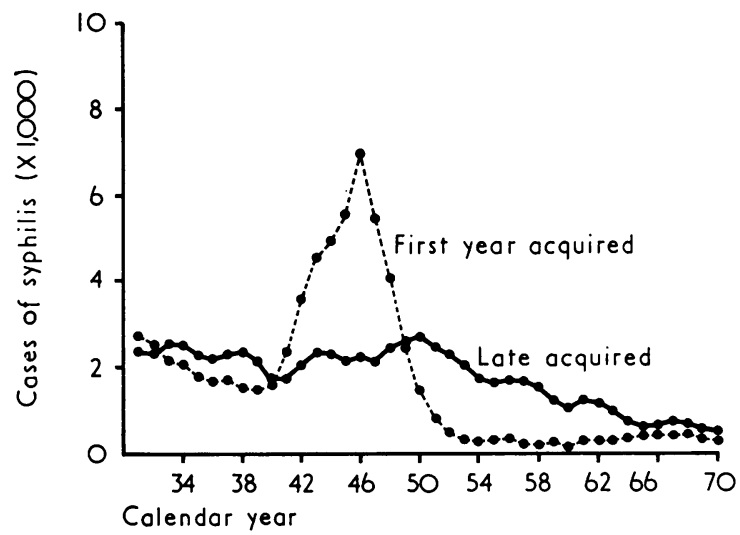

F I G. 2 Curves for females of first-year acquired discoveries and late discoveries, 1931-70

The total syphilis for 1919 and 1920 was 42,134 and 42,805 . The second peak occurred in 1946 , when the total number of infections was recorded as 23,878 .

The records of the second world war were known to have omitted an important proportion of males, who were serving in the armed forces. Nevertheless, because of the much greater weight of the first increase, it seems likely that, if there is an imbalance of late discovered cases brought forward from the first world war and those carried forward from the second world war, it would be in favour of the former. If this were true, then the 'late discovery factor' calculated from the total figures would be higher than the actual factor determining the proportion of discoveries.

The 'late discovery factor' calculated from the 40-year totals is the ratio of late discovered acquired syphilis to first-year acquired syphilis. When the ratio is calculated by decades, as shown in Table II, it varies widely in both sexes. On the other hand, if the two middle decades are added together, the male ratio 0.721 and the female ratio 0.903 , as shown in Table III, are comparable to the 40 -year total. This seems to support the hypothesis that the 'late discovery factor' may be constant throughout the 40 years and that the ratio for the 40-year period may not differ widely from the 'late discovery factor'.

TABLE I Breakdown of total figures for 1931-70 by first-year discovered and late discovered

\begin{tabular}{|c|c|c|c|c|c|c|}
\hline \multirow{2}{*}{$\operatorname{Sex}$} & \multicolumn{2}{|l|}{ Male } & \multicolumn{2}{|l|}{ Female } & \multicolumn{2}{|l|}{ Total } \\
\hline & No. & Per cent. & No. & Per cent. & No. & Per cent. \\
\hline $\begin{array}{l}\text { First-year discovered } \\
\text { Late discovered }\end{array}$ & $\begin{array}{r}125,919 \\
93,351\end{array}$ & $\begin{array}{l}57 \\
43\end{array}$ & $\begin{array}{l}66,131 \\
71,490\end{array}$ & $\begin{array}{l}48 \\
52\end{array}$ & $\begin{array}{l}192,050 \\
164,841\end{array}$ & $\begin{array}{l}54 \\
46\end{array}$ \\
\hline Total & 219,270 & 100 & 137,621 & 100 & 356,891 & 100 \\
\hline
\end{tabular}


TABLE II Ratio of first-year acquired syphilis to late discovered acquired syphilis by decades, 1931-70

(1)

\begin{tabular}{|c|c|c|c|}
\hline \multirow{2}{*}{ Sex } & \multirow{2}{*}{ Decade } & \multicolumn{2}{|c|}{ First-year discovered } \\
\hline & & No. & Per cent. \\
\hline \multirow[t]{2}{*}{ Male } & $\begin{array}{l}1931-40 \\
1941-50 \\
1951-60 \\
1961-70\end{array}$ & $\begin{array}{r}47,046 \\
58,378 \\
5,902 \\
14,593\end{array}$ & $\begin{array}{l}57 \\
69 \\
23 \\
58\end{array}$ \\
\hline & Total & 125,919 & 57 \\
\hline \multirow[t]{2}{*}{ Female } & $\begin{array}{l}1931-40 \\
1941-50 \\
1951-60 \\
1961-70\end{array}$ & $\begin{array}{r}18,908 \\
41,134 \\
3,006 \\
3,083\end{array}$ & $\begin{array}{l}44 \\
64 \\
15 \\
28\end{array}$ \\
\hline & Total & 66,131 & 48 \\
\hline
\end{tabular}

(3)

\begin{tabular}{|c|c|}
\hline \multicolumn{2}{|c|}{ Late discovered } \\
\hline No. & Per cent. \\
\hline $\begin{array}{l}35,917 \\
26,557 \\
20,151 \\
10,726\end{array}$ & $\begin{array}{l}43 \\
31 \\
77 \\
42\end{array}$ \\
\hline 93,351 & 43 \\
\hline $\begin{array}{r}23,611 \\
22,617 \\
17,231 \\
8,031\end{array}$ & $\begin{array}{l}56 \\
36 \\
85 \\
72\end{array}$ \\
\hline 71,490 & 52 \\
\hline
\end{tabular}

(5)

Ratio col. (3) $\div$ col. (1)

\begin{tabular}{l}
$0 \cdot 763$ \\
$0 \cdot 455$ \\
$3 \cdot 414$ \\
$0 \cdot 704$ \\
\hline $0 \cdot 742$ \\
\hline 1,249 \\
$0 \cdot 550$ \\
$5 \cdot 732$ \\
$2 \cdot 605$ \\
\hline 1.081
\end{tabular}

TABLE III Ratio of first-year acquired syphilis to late discovered acquired syphilis for 20 years, 1941-60 (1)

(2)

\begin{tabular}{|c|c|c|c|c|c|}
\hline \multirow{2}{*}{ Sex } & \multicolumn{2}{|c|}{ First-year discovered } & \multicolumn{2}{|c|}{ Late discovered } & \multirow[t]{2}{*}{ Ratio col. (3) $\div$ col. (1) } \\
\hline & No. & Per cent. & No. & Per cent. & \\
\hline Male & 64,280 & 58 & 46,708 & 42 & $0 \cdot 727$ \\
\hline Female & 44,140 & 53 & 39,848 & 47 & 0.903 \\
\hline
\end{tabular}

(3)

\begin{tabular}{|c|c|c|c|c|c|}
\hline \multirow{2}{*}{ Sex } & \multicolumn{2}{|c|}{ First-year discovered } & \multicolumn{2}{|c|}{ Late discovered } & \multirow[t]{2}{*}{ Ratio col. (3) $\div$ col. (1) } \\
\hline & No. & Per cent. & No. & Per cent. & \\
\hline Male & 64,280 & 58 & 46,708 & 42 & $0 \cdot 727$ \\
\hline Female & 44,140 & 53 & 39,848 & 47 & 0.903 \\
\hline
\end{tabular}

(5)

Ratio col. $(3) \div$ col. (1)

The hypothesis has been further tested by postulating various groupings of first-year acquired cases and relating them to the actual late discoveries by a constant factor. This factor was obtained by dividing the total of late discovered cases for the period selected by the actual total number of first-year acquired cases to which it was being assumed that they were related.

The grouping which was found to relate most clearly to actual late discovered cases was derived as follows. No doubt more refined methods might produce a more precise result.

Ogive curves were drawn showing an assumed cumulative time series of the discovery of late cases (Fig. 3). The curves for males and females differ in that discovery is more frequent in females in the first 10 years and more frequent in males in the second 10 years. This assumption was not made because antenatal testing and other factors might have this effect, but to obtain a better comparison of the calculated and actual findings.

10,20 , and 30-year moving averages were then calculated for first-year acquired cases of each sex. The year to which the average relates is designated by the last of the series from which it is derived. The first-year discovered group was then found by taking the appropriate proportion of the three moving averages and adding them together. An example is shown in Table IV (overleaf).

The results of calculations for the 15-year period 1956-70 are shown in Tables V and VI for males and

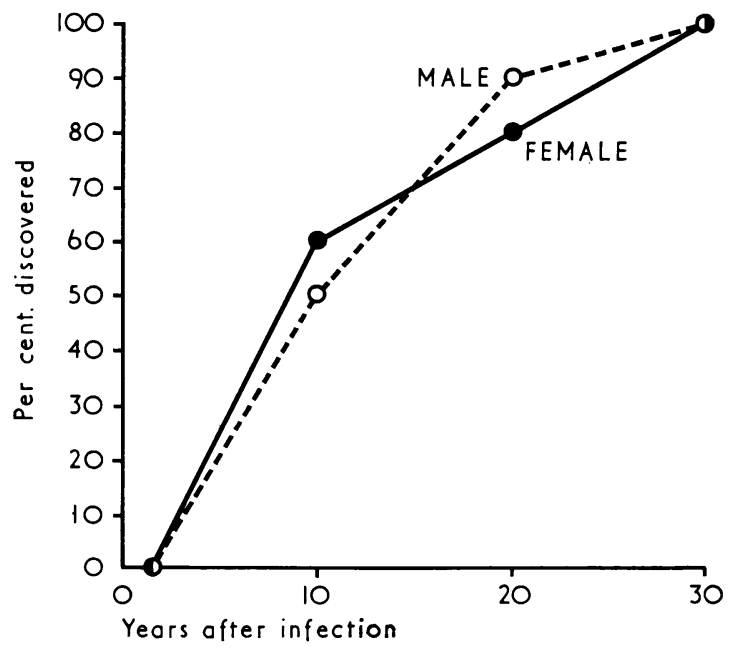

FIG. 3 Ogive curves, showing postulated rate of discovery of male and female syphilis after the first year following infection

females. The total of the annual first-year discovered groups is divided by the actual total late discoveries for the 15 years to arrive at an estimated 'late discovery factor' for both sexes. By applying the factor to each first-year discovered grouping in turn, a calculated estimate of the late discoveries for each year is obtained. 
TABLE IV Example of calculation of a first-year discovered group which is composed of proportions of three moving averages (the year 1960 is used)

\begin{tabular}{|c|c|c|c|c|c|c|c|}
\hline \multirow[t]{3}{*}{$\operatorname{Sex}$} & \multicolumn{3}{|c|}{$\begin{array}{l}\text { Moving Average } \\
\text { First-year discovered }\end{array}$} & \multicolumn{3}{|c|}{ Per cent. appropriate to group } & \multirow{2}{*}{$\begin{array}{l}\text { Total }= \\
\text { Number in group }\end{array}$} \\
\hline & 10 yrs & 20 yrs & 30 yrs & 10 yrs & 20 yrs & 30 yrs & \\
\hline & & & & 50 per cent. & 40 per cent. & 10 per cent. & \\
\hline \multirow[t]{2}{*}{ Male } & 740 & 3,174 & 3,711 & 370 & 1,297 & 371 & 2,011 \\
\hline & & & & 60 per cent. & 20 per cent. & 20 per cent. & \\
\hline Female & 301 & 2,209 & 2,102 & 181 & 442 & 420 & 1,043 \\
\hline
\end{tabular}

TABLE V Male composite moving average of first-year discovered group of acquired syphilis and actual late discovered cases used to estimate a 'late discovery factor' for the period 1956-70.

The figure calculated from the moving average is compared with the actual late discoveries

\begin{tabular}{|c|c|c|c|}
\hline \multirow[b]{3}{*}{ Year } & \multirow[t]{2}{*}{ (1) } & (2) & \multirow[t]{2}{*}{ (3) } \\
\hline & & Late discoveries & \\
\hline & $\begin{array}{l}\text { Male composite moving average } \\
(10 \text { yrs } \times 0.5 ; 20 \text { yrs } \times 0.4 ; 30 y r s \times 0.1)\end{array}$ & $\begin{array}{l}\text { Calculated } \\
\text { Col. }(1) \times 0.690\end{array}$ & Actual \\
\hline $\begin{array}{l}1956 \\
1957 \\
1958 \\
1959 \\
1960 \\
1961 \\
1962 \\
1963 \\
1964 \\
1965 \\
1966 \\
1967 \\
1968 \\
1969 \\
1970\end{array}$ & $\begin{array}{c}3,355 \\
2,858 \\
2,472 \\
2,186 \\
2,011 \\
1,885 \\
1,730 \\
1,713 \\
1,676 \\
1,654 \\
1,502 \\
1,387 \\
1,322 \\
1,290 \\
1,276\end{array}$ & $\begin{array}{r}2,315 \\
1,972 \\
1,706 \\
1,508 \\
1,388 \\
1,301 \\
1,194 \\
1,182 \\
1,156 \\
1,141 \\
1,036 \\
957 \\
912 \\
890 \\
880\end{array}$ & $\begin{array}{r}1,987 \\
1,981 \\
1,820 \\
1,576 \\
1,474 \\
1,653 \\
1,396 \\
1,127 \\
993 \\
966 \\
929 \\
966 \\
979 \\
834 \\
883\end{array}$ \\
\hline
\end{tabular}

Male late discovery factor $(F)=$ Total col. $(3) \div$ Total col. $(1)=0.690$

TABLE VI Female composite moving average of first-year discovered group of acquired syphilis and actual late discovered cases used to estimate a 'late discovery factor' for the period 1956-70.

The figure calculated from the moving average is compared with the actual late discoveries

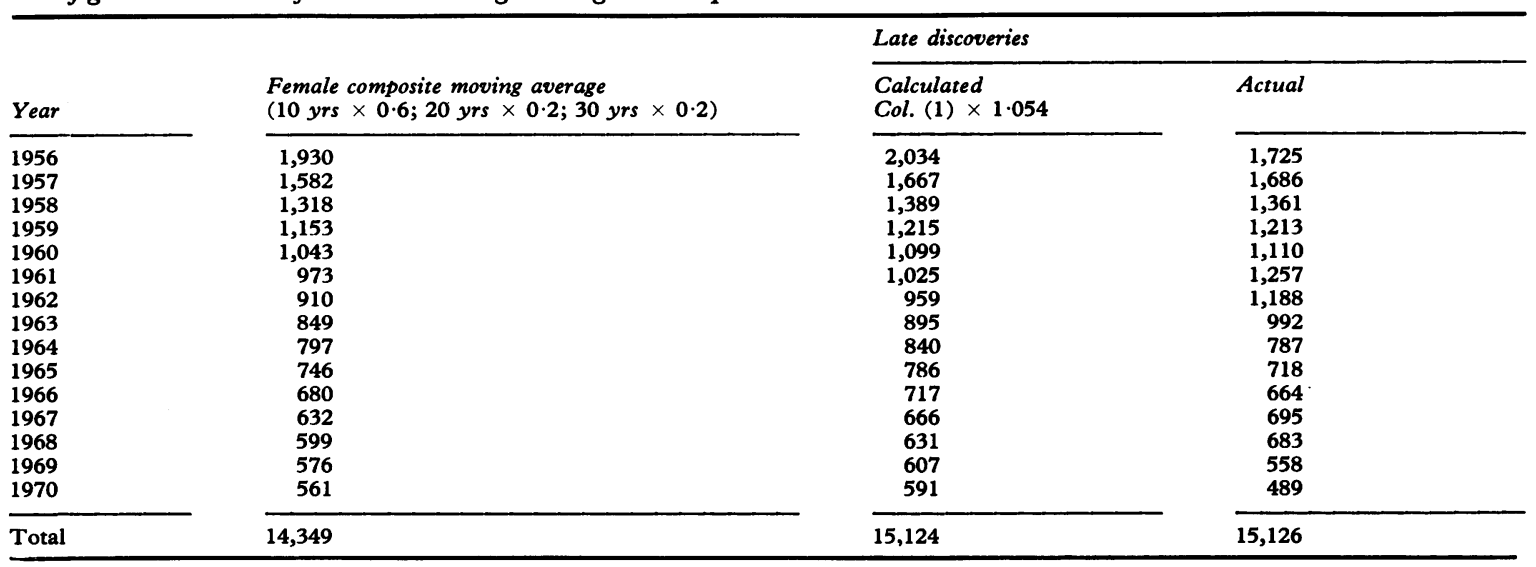

Female late discovery factor $(F)=$ Total col. $(3) \div$ Total col. $(1)=1.054$ 
The curves of the actual and calculated late discoveries are shown in Figs 4 and 5 for males and females respectively. Both show a fair match. The

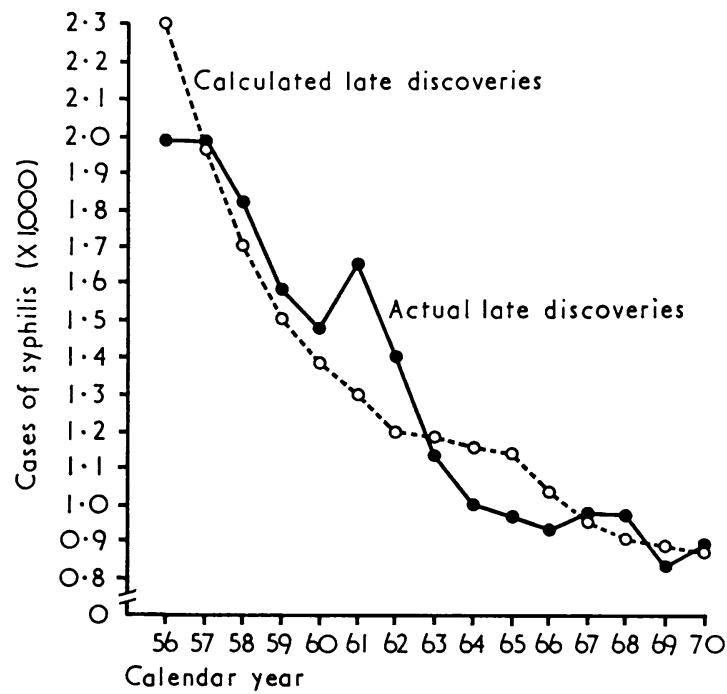

FIG. 4 Curves for males of actual and calculated late discoveries, using a composite moving average of first-year discoveries $(10$ yrs $\times 0.5 ; 20$ yrs $\times 0.4$; 30 yrs $\times 0.1)$ and a late discovery factor of 0.690 (1956-70)

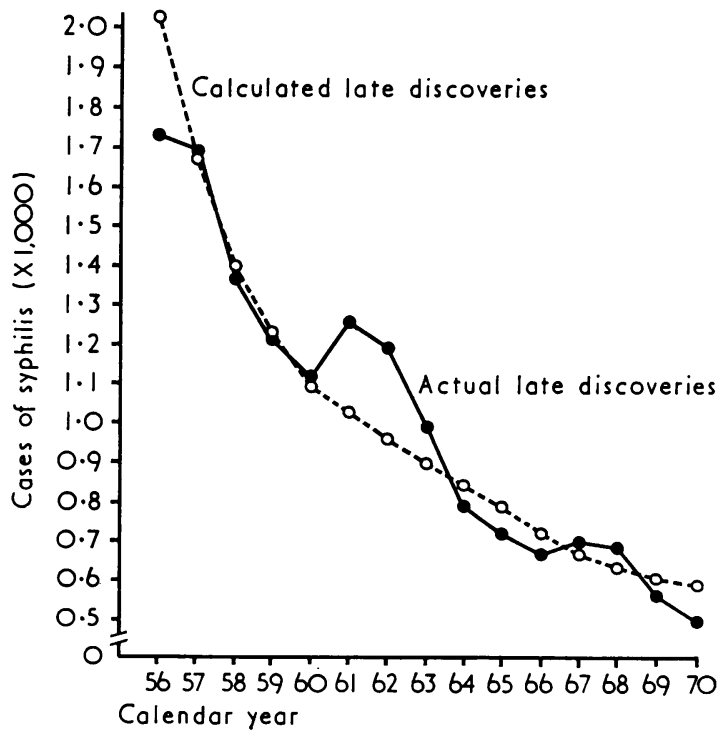

FIG. 5 Curves for females of actual and calculated late discoveries, using a composite moving average $(10 y r s \times 0.6 ; 20 y r s \times 0.2 ; 30 y r s \times 0.2)$ and $a$ late discovery factor of 1.054 (1956-70) minor peaks of the actual curves of 1961 are not repeated in the calculations. It may be that the Street Offences Act of 1959, which altered the law in relation to male homosexuality, for some reason speeded up late discovery for 2 years. Alternatively, the calculation may have smoothed out real peaks 15 years after the first-year discovered peaks of 1946 . There was a plateau in late discoveries for 1931 to 1934 which came 12 to 15 years after the first war peaks, but it is not sufficiently marked to justify any deduction.

Since the calculated curves are based on postulated figures, they can be of only general interest, but since the male and female 'late discovery factors' of 0.690 and 1.054 are so close to the factors calculated from the total of the 1931-70 period, some weight is added to the hypothesis that the true factors may be of the same order.

\section{Discussion}

There is a basis for the assumption that the incidence of undiscovered syphilis in any year during the period 1931-70 was of the order of 70 per cent. in the case of males and 100 per cent. in the case of females of the first-year infections discovered in that year. This assumption can be used to enlarge the discussion of the epidemiology of syphilis. A comparative study may provide clues on which to build hypotheses to explain the distribution of gonorrhoea. In making such comparisons, however, account must be taken of the contrasting natural histories of the two infections. Perhaps the only real similarity is that both of them are almost exclusively transmitted by sexual intercourse and that the dynamic forces that distribute them depend primarily on the pattern of sexual behaviour.

It would not have been surprising if the calculations of the late discovery factors, instead of being almost the same, had shown an increase for the period 1956 to 1970 . A relative decrease in the rate of discovery of first-year syphilis might have resulted from the masking of primary and secondary infection by 'happenstance' treatment (Schamberg, 1963; Idsøe and Guthe, 1967), if such treatment had not at the same time hindered the ultimate development of positive serology.

'Happenstance' treatment, which aborted a syphilitic infection before any pathological changes had occurred, would only come to light as an apparent reduction in the infectivity of the disease.

It would be disturbing to contemplate the possible failure to discover about half the infections occurring in one year if the total number of cases recorded had not been steadily falling. 
In order to be able to compare all the years from 1918 onwards, it is necessary to use the annual totals of all types of syphilis, since no breakdown is available for the earlier years (Fig 6). The trend of the decrease is interesting and surprisingly appears to be independent of the availability of antibiotic therapy, 'happenstance' or otherwise.

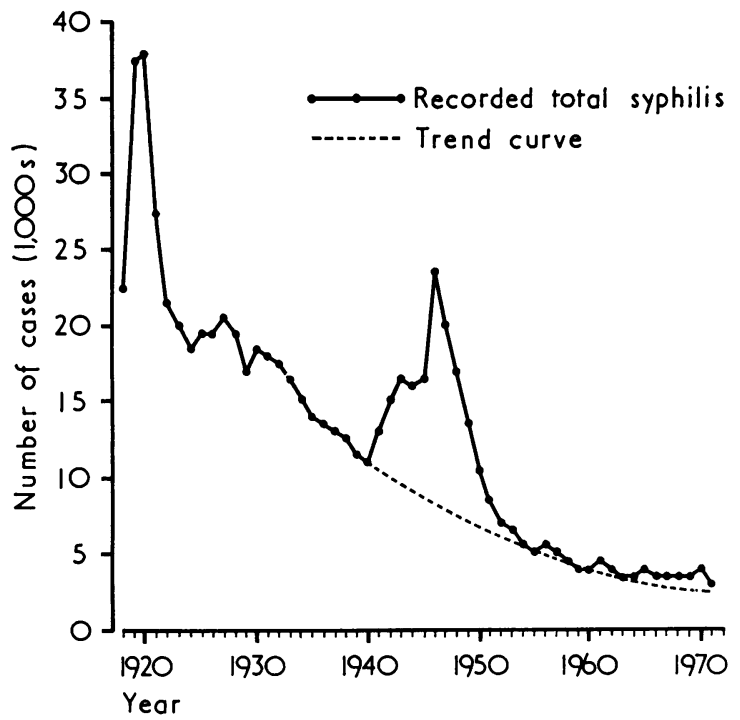

FIG. 6 Total syphilis 1918 to 1971 for England and Wales with superimposed trend curve from 1940-1971, based on a compound decrease of 5 per cent. per annum

The first world war peak of syphilis occurred in 1920 and the adjusted total is 36,119 . In 10 years the annual total had fallen to 18,883 , a decrease of 17,236 . The second world war had its syphilis peak in 1946 and the recorded total was 23,878 cases. In 10 years the annual total had fallen to 5,141, a decrease of 18,737 . The actual size of the two decreases was of the same order.

The actual decreases in annual totals over the 2-year periods $1920-22$ and $1946-48$ were 14,381 and 6,749 respectively. The decrease after the first world war was thus the more dramatic.

A period of steady decline, against a relatively stable medical and social background, began in 1930 and continued until 1940. This represents a compound decrease of 5 per cent. per year. If a trend-line starting in 1940, using this rate of decrease, is developed and shown together with the curve of actual recorded cases, the two curves come into a close relationship in the year 1954 (Fig. 6). Thereafter they follow each other closely, the trend curve improving somewhat on the actual curve.
This suggests that there is an underlying factor of importance which preceded the introduction of antibiotics which is determining the decline of the disease. This hypothesis is in accord with the observations of Moore (1951) on the records of military syphilis and various national statistics which go back 100 years. Willcox (1972) refers to the possible effect of better nutrition and improved personal hygiene in making syphilis a milder disease.

The favourable influence of this factor seems to have been overwhelmed by the dynamic forces of the change in the pattern of sexual behaviour brought about by conditions of war (Marcussen, 1953). It has reasserted itself in Great Britain notwithstanding a very substantial failure to discover and treat many cases which may have been infectious.

Even supposing the compound annual decrease of 5 per cent. of recorded cases were to continue indefinitely, it would be more than a century before indigenous chains of infection disappeared from the United Kingdom. The situation therefore calls for more rather than less effort to improve control, always bearing in mind that changes in the pattern of sexual behaviour, which may be insidious, can reverse the trend.

\section{Summary}

A 'late discovery factor' has been calculated which, when applied to the number of first-year syphilitic infections which are discovered in a particular year, provides an estimate of the incidence of undiscovered cases for the period.

The factor is derived from the proportions discovered in the first year of infection and those discovered later for the 40-year period 1931-70. By postulating the rate of late discovery of infection for males and females separately, and simulating the curves of actual late discovery, it was found that the factors for the period 1956-70 were very close to those found for the whole 40-year period.

The factor put forward for males is 0.7 and for females 1.0. It is suggested that the incidence of undiscovered cases of syphilis equals approximately 70 per cent. of the discovered infections in males and 100 per cent. of the discovered infections in females.

I should like to thank Dr. C. S. Nicol for his help and encouragement in the preparation of this paper.

\section{References}

Department of Health and Social Security (1917-70) 'On the State of the Public Health'. Annual Reports of the Chief Medical Officer. H.M.S.O., London 
Idsøe, O., and Guthe, T. (1967) Brit. F. vener. Dis., 43, 227

Marcussen, P. V. (1953) Amer. F. Syph., 37, 355

MOORE, J. E. (1951) Lancet, 1, 699

SCHAMBERG, I. L. (1963) Brit. F. vener. Dis., 39, 87

Willcox, R. R. (1972) Ibid., 48, 163

\section{Estimation de l'incidence annuelle des cas de syphilis non découverts}

\section{SOMMAIRE}

Un 'facteur de découverte tardive' a été calculé qui, quand on l'applique au nombre d'infections syphilitiques de moins d'un an découvertes pour une année particulière, fournit le moyen d'apprécier l'incidence des cas non découverts correspondant à cette période.

Ce facteur est établi d'après la proportion des cas découverts au cours de la première année de l'infection et ceux découverts plus tard, pendant la période de 40 ans allant de 1931 à 1970. En calculant le taux de découverte tardive de la maladie séparément pour les hommes et les femmes et en établissant les courbes actuelles des découvertes tardives, on a trouvé que les facteurs pour la période 1956-70 étaient très près de ceux trouvés pour l'ensemble de la période de 40 ans citée. Le facteur proposé est de 0,7 pour les hommes et de 1,0 pour les femmes. Ceci suggère que l'incidence des cas non découverts de syphilis équivaut approximativement à 70 pour cent des infections découvertes chez l'homme et à 100 pour cent chez la femme. 